\title{
Constraints Facing Women's Career Advancement in the Hospitality Industry in Rwanda: Case of Selected Hotels in Kigali
}

\author{
Dr.Isaboke Peter Kennedy Nyataya, Phd
}

\begin{abstract}
Sociology-Senior Lecturer, Director of Academic Affairs and Quality Assurance, University of Tourism, Technology and Business Studies (Utb), Gisenyi Campus
\end{abstract}

Nyaboga Enock Kiage Ma

Project Management-Assistant Lecturer, Director of Academics, Examinations and Quality Assurance, University of Tourism, Technology and Business Studies (Utb), Kigali Main Campus

\begin{abstract}
Traditionally, world all over, men and women's roles differed greatly due to the fact that division of labour was based on ones sex. Changes observed, today, in the forms of structure of employment, gender equality campaigns and policy guidelines are viewed as not being good enough to eliminate employment disparity by gender. There still exists an unfair share of key managerial and executive positions among women and men in all the sectors of the present Rwandan economy, the hotel industry included.
\end{abstract}

The present study was conducted mainly with a view to identify the main factors that influence women's career advancement in the hotel industry, to examine the role of female workers in the industry besides seeking and analysing the workers' views on gender disparity within the hotel industry.

The sample size of the study comprised a total of fifty (50) respondents drawn from the selected hotels: Three Star Hotels, Four Star Hotels and Five Star Hotels operating in the City of Kigali. The respondents comprised human resource managers, heads of housekeeping department, heads of food production department, sales and marketing department, food and beverage services department and heads of front office department.

The principal findings of the study were: women were found to be labeled as sex objects, slow, moody and sickly and hence, the aforementioned seen as main cause of gender disparity in the hotel industry. The number of qualified women and with experience for senior positions is lower than that of men. Besides, management priorities, family responsibilities, recruitment procedures and the nature of works that favor men were identified as other factors contributing to gender disparity observed in the industry. In addition, recruitment based on family relations and social networks were pointed out as for factors for the aforesaid disparity.

The researchers recommend that women employees should be given more opportunities for training on leadership and management in the hotel industry in particular and in other industries in general, with a view to equipping them with the needed professional skills in planning and in general management as well. Besides, this may improve their level of confidence and self-esteem. The employers should not only encourage but also make deliberate efforts to support women who have the relevant qualifications to go for senior positions in the hotel industry.

Keywords: constraints, career advancement, hospitality industry, hotel industry and gender

\section{INTRODUCTION}

Gender disparity witnessed in the present society, has become an issue of concern in all sectors of the economy, including the hospitality industry in which it has been observed that certain departments and positions are dominated by men and whereas others are dominated by women. Disparity is also expressed in terms of job position, department, age, income and educational level. Sparrowe and Iverson (1999), have observed that there is a disparity of income between male and female employees in the hospitality industry, with females earning less than their male counterparts. Manwa and Black (2002) and Thrane (2007), too, have noted that there is gender differences in promotions to managerial positions, wherein men are overrepresented in preferred positions that pay better. Part of the reason for this disparity is taken to be that female employees are likely to interrupt their working lives through their marriages and child rearing activities. According to Kattara (2005), age, work experience and work-family conflicts are some of the factors that influence and prevent female 
employees from reaching the top managerial positions within the Egyptian hotel industry. The business environment of the hospitality industry, long working hours and high degrees of mobility, to a large extent, support males' advancement in their professional careers. Women face a number of visible and invisible barriers and challenges such as motherhood, discrimination and stereotyping in society. It is noted that in the recent past, the number of women who are undertaking hospitality and tourism courses has been steadily growing. However, gender disparity seems to live in the hospitality industry, which in turn, brings the concern on recruitment and compensation decisions as the factors that could influence those decisions.

\subsection{Background of the Study}

Today, the entry of women into the hospitality industry especially in the hotel industry is high compared with that of men. However, in spite of the strong overall female presence, it is observed that there is an unequal distribution of the key managerial and executive positions in the industry among women and men.

The present research was about women's career advancement in the hotel industry in the following career paths; operators or waitresses, heads of food and beverage, assistant managers and general managers. The research focused on training, experience, qualifications and promotions in relation to job opportunities and employers' preferences. The researchers were focused their attention on understanding the issue of gender disparity in the departments of; front office, house keeping, food and beverage, accounts, food production, marketing and sales, maintenance, security and control.

The role of women in management is pertinent to businesses to recognise that female managers are part of a talented pool that is essential to be retained and developed. Rwandan Parliament, by the December of 2011, had the highest number of women members in the world, fifty six per cent (56\%). In the hospitality industry, more so, in the hotel sector, according to the Rwandan Hotel Association (2008) revealed that sixty eight $(68 \%)$ of the total number of employees hired was women whereas the remaining thirty two per cent $(32 \%)$ was men. The same was witnessed by the number of female students (62\%) as compared to that of male students (38\%) enrolled in hospitality schools and higher learning institutions in Rwanda, by then. However, contrary, in the hospitality industry as seen, today, there is a decrease in the number of women holding key managerial positions in the industry as compared to that of men.

\subsection{Problem Statement}

Traditionally in Rwanda, men and women play different roles in society. Men used to view women's mainly to be household related duties as such as house cleaning, cooking foods and looking after children. This was based on the traditional gender division of labour. The present changes in the form of structure of employment, gender equality campaigns and policies to a great extent, are yet to eliminate employment disparity among women and men witnessed in the country, today.

The impact of economic development and changes in education, family organisation and female labour force participation varies across individuals, countries and regions and ultimately depends on institutions as well as on individual preferences.

Despite the positive impact has come with the aforementioned conditions, still then, what is clearly observed, today, is the number of women in top management in the hospitality industry is still low. Hence, this calls for an investigation into the constraints facing women in the course of climbing to the top management positions, with emphasis on the cultural influence on job preferences, their experiences in the hotel work, their level of training, work related conditions and family responsibilities. Female labor force participation, according to the International Labour Organisation (ILO, 2010a), Rwanda is among the countries with the highest female labour force participation rate, eighty eight $(88 \%)$. However, there are exists few women in managerial positions in the hotel industry in the country.

The study explored and analysed the constraints facing women's career advancement in the hospitality industry as perceived by human resource managers and other departmental managers or supervisors.

\subsection{Specific Objectives of the Study}

The present study was guided by the following specific objectives:

1. To identify the factors that influence women's career advancement in the hotel industry 
2. To examine the role of female workers in the hotel industry

3. To assess the career aspirations of female workers in the hotel industry

4. To seek the workers' views on gender disparity within the hotel industry

\subsection{Research Questions}

- What are the factors influencing women's career advancement in hotel industry?

- What is the role of female workers in the hotel industry?

- What career aspirations do female workers have in the hotel industry?

- What are the workers' views on gender disparities within the hotel industry?

\subsection{Significance of the Study}

The subject of gender equality and women empowerment is of great interest to many as envisioned in the Millennium Development Goals and Rwanda's vision2020. It is therefore a subject of great interest to the national governments, societies and universities as well for policy development. However, there is scant data available on women in key positions in the country's hospitality industry.

As trainers in the tourism and hospitality industry, our focus on conscious- awareness raising among female learners awareness with a view to preparing and encouraging them to take up managerial positions in the hotel industry. Hence, the present research also aimed at establishing and promoting job satisfaction and organisational commitment to the issue of gender equality in the industry.

\subsection{Scope of the Study}

The findings of the study if adopted may lead to generation of data on cultural aspects, family responsibilities perceptions of community, employers' perceptions, working hours, environment, training needs, experience, skills (problem-solving, multitask, team spirit and communication) and women specific characteristics that can play a significant role in women's participation in the key managerial positions in the hospitality industry in present Rwanda.

\section{LiterATURE REVIEW}

A number of studies already conducted on the role of women and challenges facing female workers to advance to top management in the industry and related areas were reviewed with a view to acquiring in-depth understanding of the subject matter.

\subsection{Hospitality Industry}

The hospitality sector includes all businesses that provide food, beverages and accommodation services as well. This include: restaurants, pubs, bars and clubs, hotels, contact catering and hospitality services. The tourism and hospitality industries are some of the world's largest sectors, amounting to over ten percent (10\%) of the Gross Domestic Product (GDP) (Cooper et al., 2005:4) and employ eight per cent $(8 \%)$ of the global workforce. The hospitality industry has experienced huge growth in the recent years. In the years 1990 to 1998, it recorded a growth of over twenty five $(25 \%)$ in the number of units (Brotherton, 2003) and a total of 29.4 million bed spaces in hotels and similar establishments worldwide in 1997 (WTO, 2000).

In Rwanda, the hospitality industry has been growing steadily and has been observed to be employing more women than men. Rwanda's constitution espouses strong women's representation in decision making, in particular a thirty percent $(30 \%)$ minimum representation in policy making and public sector management. The said has contributed significantly to an increase in number of parliamentary seats held by women from $17 \%$ in 1994 to $56 \%$ in 2010 . Moreover, gender profiles are conducted periodically to inform evidence-based policy making for enhanced gender equality.

\subsection{Gender Equality}

'Gender' refers to the roles, responsibilities, attributes and power relations that are socially constructed by and assigned to men and women of a given society or community. These constructs vary greatly according to culture, geographic region, socioeconomic status and context and, change from time to time. Women are major contributors, participants and above all, key promoters of 
economic growth in the developing countries, yet, they continue to face social barriers and inequalities that prevent them from realising their full potentials. Research has established that women generally earn less than men for the same work and their jobs are concentrated in lower paying industries and the informal sector. The concept of gender also denotes the ways people believe that men and women should behave in particular ways and the assumptions made about their characteristics and their capacities. In the work place there are demands for gender equality in recruitment and selection as noted by Hermsen and Vanneman, (2004). Brink et al (2006), observed that even if gender is not explicitly specified in many recruitment and selection policies and practices, gender equality in appointments is not assured Thus, their gender is one of the barriers to the recruitment and selection of women and to their career progression.

\subsection{Gender Role Disparity Analysis}

Gender differences in the hospitality labour market concentrates on different occupational distribution. Research has shown the presence of occupational disparity between men and women. The said disparity has been classified in two : horizontal disparity which refers to those cases in which there are occupations that are clearly dominated by only one gender and vertical disparity which refers to those situations in which women's percentage in top management is very small in relation to men' proportion.

A survey conducted by the National Institute of Statistics of Rwanda (2011) indicated that women are managers of about twenty six percent (26\%) of all the establishments in country. The prevalence of female managers is highest in Kigali City with about forty three percent (43\%) while other provinces indicate less than twenty four (24\%). Accommodation and food service activities employed people on the basis of their gender as noted. During the period a total of 6969 males and a total of 4449 females who represented $61 \%$ and $39 \%$, respectively, was employed.

In 2012 tourism and hospitality sector had a total of 20,860 employees comprising of $35.7 \%$ women and $64.3 \%$ men (RDB, 2012). Restaurants, hotels and accommodations had 16,261 employees with 6,035 women and 9,650 men which is $37.1 \%$ women and $62.9 \%$ men.

Hence, it is clear that the number of male employees had gone up by almost $2 \%$ while that of female went down by $2 \%$. In the year 2012, in the Rwanda skills Survey Report, two challenges were identified. The first challenge is poor customer care and the second is few qualified staff working in the tourism and hospitality industry. Large establishments employed 7026 laborers whereby 35\% were women mainly working as waiters and cooks. The table below shows gender disparity in the four departments under study in large establishments.

\begin{tabular}{|l|l|l|l|}
\hline Hotel Department & Women & Men & \% of women staff \\
\hline Hotel Managers & 38 & 158 & $19.4 \%$ \\
\hline Front Office & 25 & 92 & $21.4 \%$ \\
\hline Food \& Beaverage & 15 & 104 & $12.6 \%$ \\
\hline Housekeeping & 81 & 102 & $44.3 \%$ \\
\hline
\end{tabular}

In the medium establishments, women accounted for about $36.4 \%$ of the labor units who worked mainly as waiters and cooks whereas in the small establishments, women accounted for about $53.8 \%$ , who worked mainly as receptionists and housekeepers. Women accounted for about $7 \%$ of total managers of the restaurants. There were no women found to be serving as managers in food and beverage department in the large establishments. However, in the housekeeping, women accounted for about $78.3 \%$ in large restaurants. In medium restaurants, women managers accounted for about $7.3 \%$ and $55 \%$ in the food and beverage department as pointed out by the Rwanda Development Board, (2012).

From the above report it is interesting to note the number of women working in hotels depended on the size of the hotel.

\subsection{Factors Influencing Women's Career Advancement in the Hotel Industry}

A number of factors have been identified by researchers which are believed to contributing toward the professional marginalisation of women. These include gender stereotyping (Heilman, 2001), a lack of role models, mentors and peers for women in the workplace (Noe, 1988) and the 'glass ceiling' (Davidson and Cooper, 1992; Reich, 1995). These factors influence and combine with women's self- 
perceptions and contribute to low self-confidence, a lack of self-esteem and a failure to aspire to senior positions (Davidson and Cooper, 1992).

According to Brownell (1994), the unfair share in number gave rise to the "glass ceiling" concept defined by the American department of labour as a "composite of artificial barriers based on attitudinal or organizational bias that prevents qualified women from advancing upward in their organizations into senior level positions'. Hewlett and Luce (2005) and Belkin (2003) identified a number of 'push' and 'pull' factors which make women leave the work place. Women are 'pushed' away by their organisations because they find their jobs meaningless, are not exposed to more career opportunities, have minimal mentoring support, are not acknowledged for their work and experience low job satisfaction. At the same time, women take time attending to family demands and needs such as bearing children, raising children, and attending to elderly parents and traditional home division of labour,as they observed.

\section{RESEARCH METHODOLOGY}

This section deals with research design, population and sampling techniques, research instruments, data collection and analysis.

\subsection{Research Design}

The study adopted the descriptive research design and case study approach

\subsection{Sample Size of the Study}

The sample size of the study comprised a total of fifty (50) respondents drawn from the selected hotels: Three Star Hotels, Four Star Hotels and Five Star Hotels operating in the City of Kigali. The respondents comprised human resource managers, heads of housekeeping department, heads of food production department, sales and marketing department, food and beverage services department and heads of front office department.

The specific respondents for the study included the managers, human resource managers, supervisors, operators and female workers. A total of five human resource managers, five female senior managers in the hotels and twenty hotel ordinary employees.

\subsection{Sampling Techniques}

Purposive sampling technique was used in identifying from the respondents for the study.

\subsection{Sources of Data}

Primary data was obtained through interviews, questionnaire focus group discussions.

Secondary data was collected through books, articles, journals and the reports.

\section{Methods of Data Collection}

The researchers interviewed the employees of the selected hotels with a view to obtaining desired data. Questionnaires administered to the human resources managers of the hotels under the present study. Focus group Discussions were also held with various respondents to elicit the required data

\subsection{Data Analysis}

The collected was analysed through the use of Statistical Package for Social Sciences and Content Analysis Technique.

\section{Results}

\subsection{Demographic Characteristics of the Respondents}

The majority of the respondents was found to belong to the age-category of 18-37, which represented eighty percent $(80 \%)$ of the total respondents covered in the study whereas the remaining twenty percent (20\%) is those above 37 years old. It is an indication that the majority the workers in the industry are the youth. Sixty percent $(60 \%)$ of the respondents is single while forty percent $(40 \%)$ is married. Thirty percent $(30 \%)$ of respondents indicated that its level of income was below 150000 Rwandan Francs. Another thirty percent (30\%) earned between 150000-300000 Rwandan Francs whereas forty percent (40\%) of respondents earned above 300000 Rwandan francs.

All the senior staff members were observed to earn over 150000 Rwandan Francs. Sixty percent $(60 \%)$ of the respondents indicated that their level of experience is less than three years and forty 
percent $(40 \%)$ of them had over three years of experience in the hotel industry. Hence, this shows that the hospitality industry in Rwanda is still in its infant stage. As regards their educational status, Sixty percent $(60 \%)$ of the respondents were university degree holders while forty percent $(40 \%)$ were diploma holders. An interview with the human resource managers indicated that the number of professionals is increasing with a high number of degree holders entering the job market.

\subsection{Gender Participation in 2012 and in 2013}

It was noteworthy that the number of women is increasing in all the departments surveyed for the study. In 2012, the percentage of women from three star hotels to five star hotels stood at about forty four per cent $(44 \%)$ whereas in 2013 , it rose to about fifty two percent $(52 \%)$. Food and beverage department also indicated an increase of women participation from about twelve percent $(12 \%)$ in 2012 to about eighteen percent (18\%) in 2013. Though there has been an increase in the number of women in the department, the number is still considerably lower than that of men in the same area.

In the front office, the number of women increased from about twenty one percent (21) in 2012 to thirty percent $(30 \%)$ in 2013 . However, the number of women advancing to the position of hotel managers has not shown any significant increase. It was about nineteen percent (19)\% in 2012 and twenty percent ( $20 \%$ ) in 2013.

\subsection{Gender Distribution in the Hospitality Industry}

The number of men played in the industry in 2011 was $61 \%$ while that of women was 39\%. In 2012, the number of men rose to $62.9 \%$ while that of women went down to $37.1 \%$. The drop in the number of women was noted to have been due to inadequate /lack of professionalism for a good number of the hotels were looking for qualified personnel after the classification of the hotels was done. The present researchers observed that the starred (Three, Four and Five) hotels indicated that the number of women employed was $45.4 \%$ while that of men was $54.6 \%$. However; it is mention worthy that the number of women professionals is gradually increasing. Hospitality schools in the country sixty two percent $(62 \%)$ the total number of registered students was women and thirty eight percent (38\%) men. Given this fact the question of this research was to find out why few women in senior positions despite their growing number in the hospitality industry.

Table1. Employment by Gender in the Hospitality Industry

\begin{tabular}{|l|l|l|l|l|l|l|}
\hline $\begin{array}{l}\text { Hotel } \\
\text { Department }\end{array}$ & Women & Men & $\begin{array}{l}\text { \% of women staff 2012 } \\
\text { in Classified hotels }\end{array}$ & Women & Men & $\begin{array}{l}\text { \% of women staff 2013 in } \\
3^{*}-5 * \text { hotels }\end{array}$ \\
\hline Hotel Mgr & 38 & 158 & $19.4 \%$ & 2 & 9 & $18.2 \%$ \\
\hline Front Office & 25 & 92 & $21.4 \%$ & 5 & 7 & $41.7 \%$ \\
\hline F \& B & 15 & 104 & $12.6 \%$ & 4 & 7 & $36.4 \%$ \\
\hline Hsekeeping & 81 & 102 & $44.3 \%$ & 6 & 4 & $60 \%$ \\
\hline
\end{tabular}

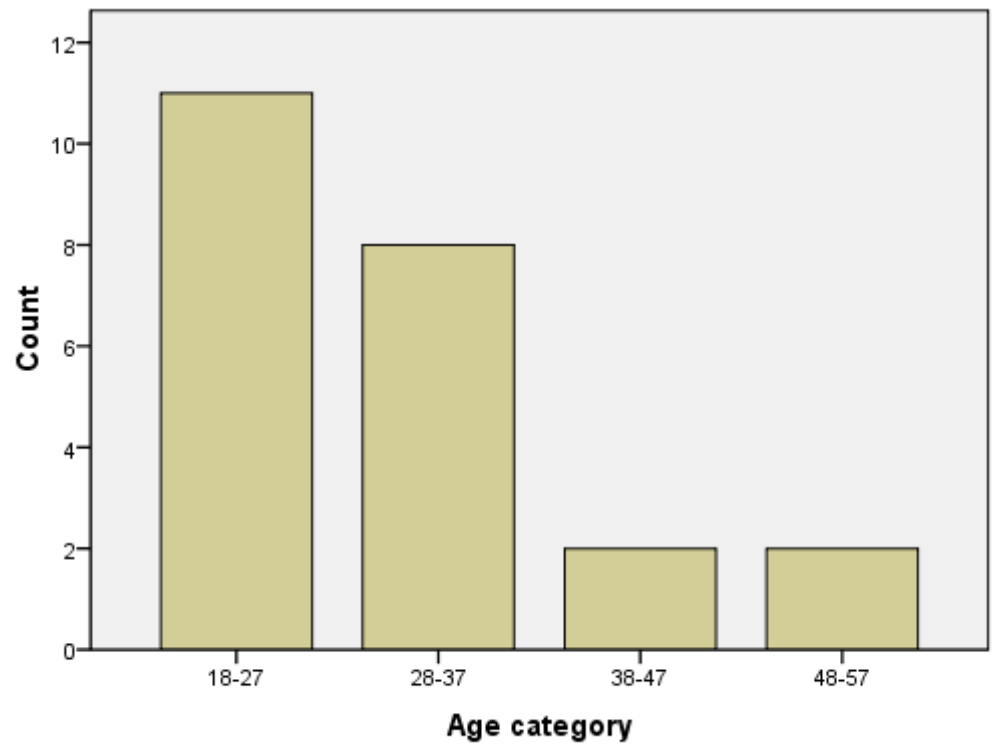

Figure1. Age Category 


\subsection{Discrimination at Work}

It was noted that both men and women were treated equally at work. However, an inquiry made from the female employees at the operation department indicated that some employees were not aware of the criteria used in rewarding the staff. Women were said to be labeled as sex objects (young and beautiful), slow, moody and sickly. For instance it was understood that some hotels preferred men to women as due to management's fears some customers visit the hotels with hidden motives of seeking friendship/love affair relationships with the women serving at the office, which, obviously, which will affect their performance and hence, lead to poor services rendered by the hotel to other customers in general.

Human resource managers observed that unfairness between men and women in the industry is seen when expectant female workers are considered unproductive as they enjoy maternity benefits while even when not working as their men counterparts during the period. It is also an industrial practice to have men in the portage work in front and back house.

\subsection{Female Career Aspiration}

The researchers found that female employees were willing to work in all the departments of the hotel. The respondents strongly agreed that women desire to be promoted to higher positions and work on full-time. However, they also indicated that they required flexible working hours in order to meet home demands.

\subsection{Factors Influencing Salary /Rewards and Promotions}

It was observed that rewards in the hotel industry in Rwanda were based on experience and skills portrayed by the employees concerned. The respondents pointed out that high level of competence at work and the contribution of the employee to the performance of the hotel were regarded as key determinants for promotions in the industry. Employees with less qualification and low performance at work were seen to earn less than those with the opposite requirements. Newly employed staffs began with less payment. Other factors that influenced compensation and promotion included age and gender as indicated by employees who had been recruited and with few years of experience. Experience and Skills and outstanding performance were identified by the majority $(65 \%)$ of the respondents as key factors determining the employees 'salaries rewards and promotions. Whereas twenty five (25\%) identified educational qualifications and other mentioned age (5\%) and gender the remaining five per cent $(5 \%)$.

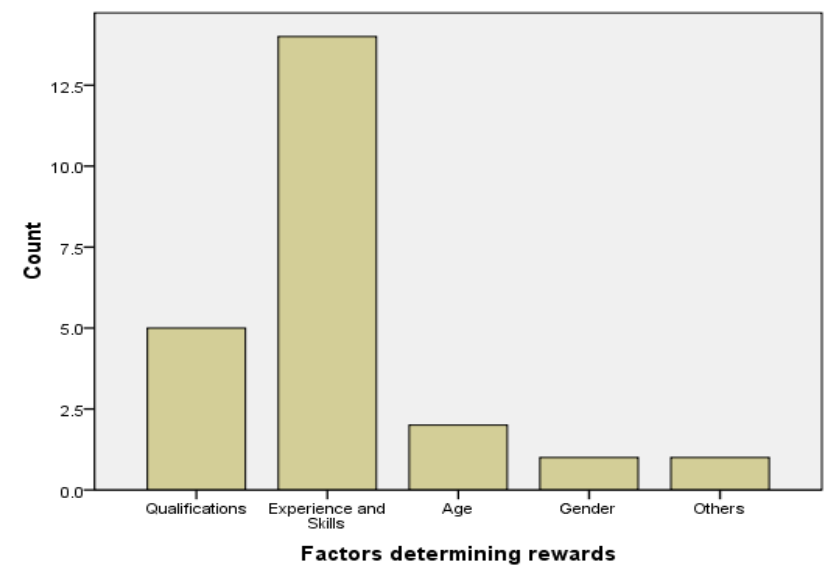

Figure2. Factors Determining Salary/Rewards and Promotions

\subsection{Departments with More Women than Men}

Four departments were compared; housekeeping, front office, food and beverage services and, sales and marketing. It was observed that the majority of women employees belong to housekeeping department. The respondents stated that women are more trustworthy than men, positive attitudes and are more effective and suitable for the job then their men counterparts, as major reasons for their high number in the department. However, female employees were found to be low in other departments such as front office, food and beverage service because the tasks performed at these departments are considered to be fit for men who have energy and endurance, they pointed out. 


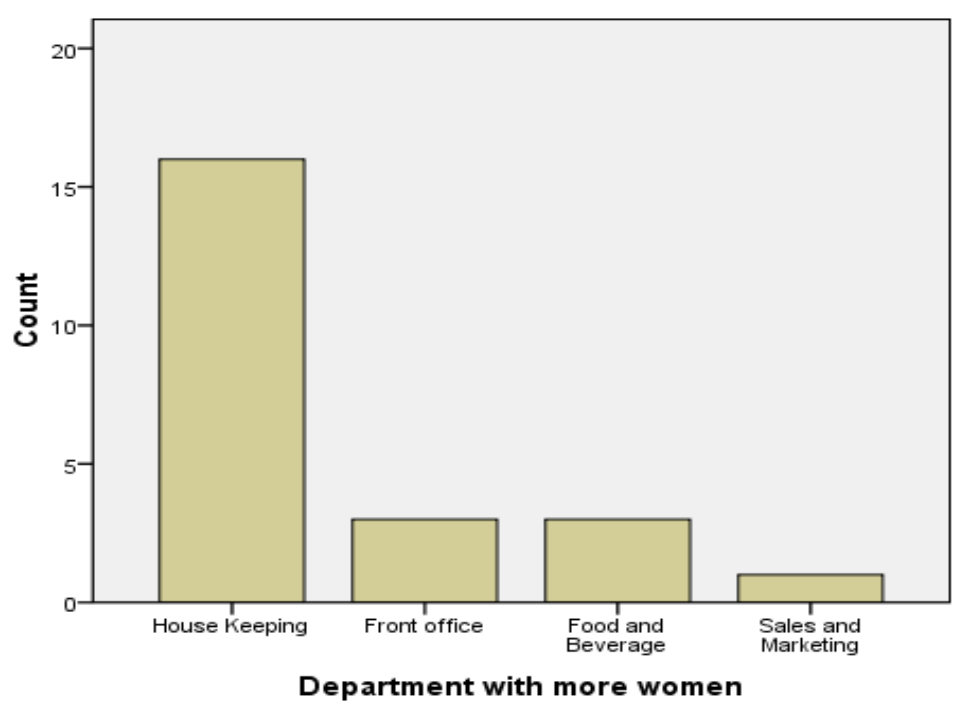

Figure3. Departments with more women than men

\subsection{Women's Career Goals and Aspirations}

The female respondents asserted that women have career ambitions even advancing to senior management in the hotel industry or even own hotel for self employment. They added, they, too, aspire for promotions and opportunities for professional development. They were also in agreement that promotions should be based on qualifications and performance as well.

\subsection{Causes of Gender Disparity}

Through the interviews conducted with the selected respondents for the study, indicated that main causes of the present gender disparity in the industry is the fact that the number of qualified women for senior positions is lower than that of men. Other causes mentioned included, the management priorities, recruitment procedures and the nature of work that favors men. For instance, one of the human resource managers pointed out that they recruited hardworking and employees of with vast experience in the industry. Sometimes recruitment is based on family and social networks as said by the respondents.

\subsection{Factors Influencing the Selection/Recruitment of Employees}

The study showed that experience and skills as pointed by about $50 \%$ of the respondents), was the main factors influencing the selection of employees. Educational and professional qualificaions, social networks, age and gender were also noted to be contributing factors towards the selections of employees in the hotel industry. According to the senior managers in the three, the four and the five stars hotels in kigali, gender does not play a significant role in selection of employees to senior positions. However, because of the need to employ someone is trustworthy and committed, family and social networks were important factors for the selection to such positions.

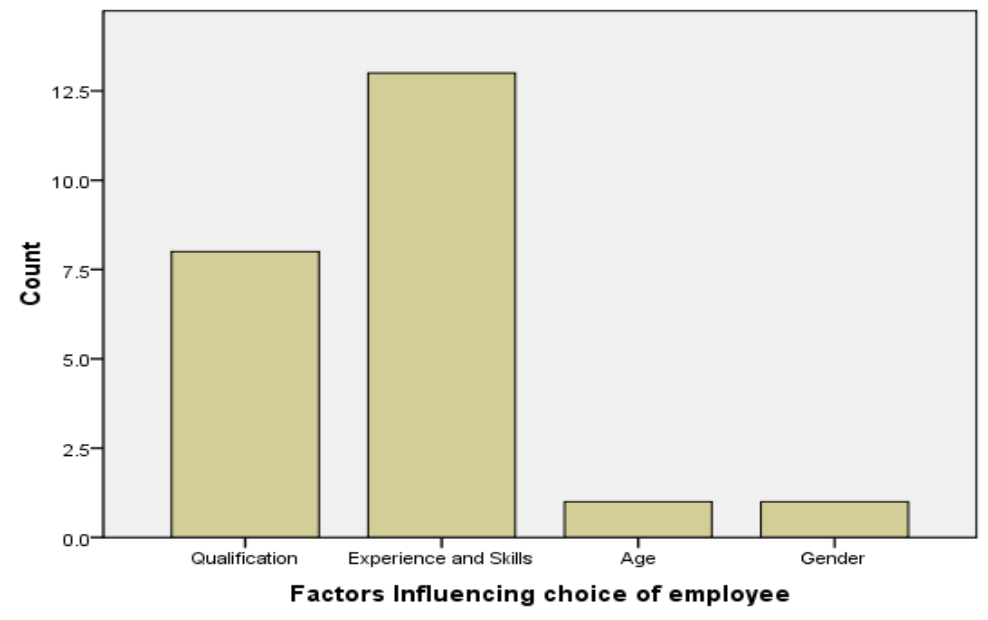

Figue4. Factors Influencing Selection/Choice of Employees 


\subsection{Barriers towards Female Employees' Advancement to Senior Positions}

The respondents of the present study, identified lack of relevant training, lack of patience and tolerance, tiredness and overstress experienced with dependents' needs especially among the single or widowed mothers, lack of confidence and self esteem change of attitude and lack of motivation from employers as key barriers facing female employees from advancing to top positions in the industry. Other barriers, stated, included low salaries and poor contracts. The Managers were of the same opinion that gender disparity in the industry was as the result of lack of motivation from employers, lack of patience, nature of work and family responsibilities.

The key constraints female employees faced, as pointed out by the respondents, were lack of experience ,Family responsibilities, education al level, corporate malpractices, lack of networking, discrimination and lack of women mentors, among others.

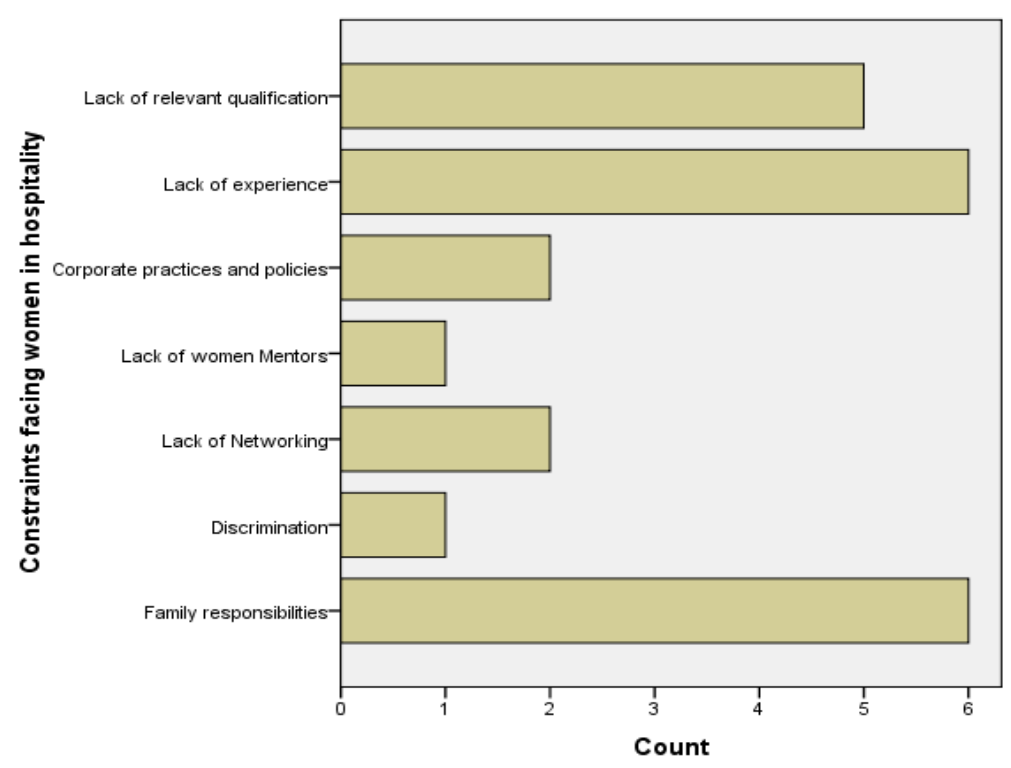

Figure5. Constraints Female Employees Face in the Hospitality Industry

\section{CONCluSion AND RECOMMENDATIONS}

Women employees should be offered adequate opportunities for training on leadership and management with a view to equipping themselves with the necessary skills to facilitate in planning coordinate and control the activities undertaken in the hospitality industry in Rwanda. This will also improve their confidence and self-esteem. The employers should encourage and support women who have the relevant qualifications to occupy the senior positions. They should set favorable policies and reward system that motivates staff. The government of Rwanda should continue to promote women participation in management through policy implementation, training, advocacy and role models.

\section{REFERENCES}

[1] Davidson, M.J. \& Cooper, C.L. (1992). Shattering the Glass Ceiling: The Woman Manager. London: Paul Chapman Publishing England.

[2] Hartley, J.F., (1994) "Case studies in organizational research", in Cassell, C.M and

[3] Symon, G. (Eds), Qualitative Methods in Organizational Research: A Practical Guide, Sage, London.

[4] Heilman, M. (2001). Description and Prescription: How gender stereotypes prevent

[5] women's ascent up the organizational ladder. Journal of Social Issues, 57(4): 657- 674.

[6] Kattara, H. (2005). Career Challenges for Female Managers in Egyptian Hotels,

[7] International Journal of Contemporary Hospitality Management, Vol. 17(3), 238-251.

[8] Lisa M. G. (Ed.) (2008). The Sage Encyclopedia of Qualitative Research Methods. Sage: Thousand Oaks, CA, Vol.2, pp.697-698.

[9] Noe, R. (1988). Women and Mentoring: A Review and Research Agenda. 
[10] The Academy of Management Review, 13(1): 65-78.

[11] Sparrowe, R.T. and Iverson, K.M. (1999), Cracks in the Glass Ceiling?

[12] An Empirical Study of Gender Differences in Income in the Hospitality Industry, Journal of Hospitality and Tourism Research, Vol. 23(1), 4-20.

[13] Thrane, C (2007), Earnings Differentiation in the Tourism Industry: Gender, Human Capital and Socio-demographic effects, Tourism Management, Vol. 29. 514-524.

[14] Vanneman, R. et al, (2004). Gender Inequality at Work. Report prepared for the Russell Sage Foundation and Population Reference Bureau

[15] Sparrowe, R.T. and Iverson, K.M.(1999), Cracks in the Glass Ceiling?

[16] An Empirical Study of Gender Differences in Income in the Hospitality Industry, Journal of Hospitality and Tourism Research, Vol. 23(1), 4-20.

[17] Thrane, C (2007), Earnings Differentiation in the Tourism Industry: Gender, Human Capital and Socio-demographic effects, Tourism Management, Vol. 29. 514-524.

[18] Republic of Rwanda, (August, 2011). Establishment Census. Kigali-Rwanda

[19] Rwanda Development Board (2012), Rwanda Skills Survey 2012; Tourism and Hospitality Sector Report. Kigali-Rwanda.

[20] Republic of Rwanda, (August, 2011). Establishment Census. Kigali-Rwanda

[21] Rwanda Development Board (2012), Rwanda Skills Survey 2012; Tourism and Hospitality Sector Report. Kigali-Rwanda.

[22] Reich, R. (1995). Good for Business: Making Full Use of the Nations Human Capital.

[23] Federal Glass Ceiling Commission, Washington DC. Http://www.dol.gov/oasam/ programs/ history/reich/reports/ceiling.pdf, (accessed on $20^{\text {th }}$ November 2012). 